framum

Sociológico

\section{Forum Sociológico}

Série II

$36 \mid 2020$

Viver a mobilidade: Percursos, permanências e registos

\title{
Desenhando a mobilidade. A potencialidade do sketching nos estudos de mobilidade
}

Drawing mobility. The potential of sketching for mobility studies

Rosalina Pisco Costa, Catarina Sales Oliveira e A Márcia Barbosa

\section{(2) OpenEdition \\ Journals}

Edição electrónica

URL: https://journals.openedition.org/sociologico/9216

DOI: $10.4000 /$ sociologico.9216

ISSN: $2182-7427$

Editora

CICS.NOVA - Centro Interdisciplinar de Ciências Sociais da Universidade Nova de Lisboa

Edição impressa

Paginação: 67-76

ISSN: 0872-8380

Refêrencia eletrónica

Rosalina Pisco Costa, Catarina Sales Oliveira e A Márcia Barbosa, «Desenhando a mobilidade. A potencialidade do sketching nos estudos de mobilidade », Forum Sociológico [Online], 36 | 2020, posto online no dia 08 outubro 2020, consultado o 30 março 2022. URL: http://journals.openedition.org/ sociologico/9216 ; DOI: https://doi.org/10.4000/sociologico.9216 


\title{
DESENHANDO A MOBILIDADE. A POTENCIALIDADE DO SKETCHING NOS ESTUDOS DE MOBILIDADE
}

\section{DRAWING MOBILITY. THE POTENTIAL OF SKETCHING FOR MOBILITY STUDIES}

\author{
Rosalina Pisco Costa \\ Departamento de Sociologia, Universidade de Évora \& CICS.NOVA.UÉvora - Centro Interdisciplinar de Ciências Sociais \\ Catarina Sales Oliveira \\ Faculdade de Ciências Sociais e Humanas, Universidade da Beira Interior \& CIES-IUL - Centro de Investigação e Estudos \\ de Sociologia
}

\author{
A. Márcia Barbosa \\ CICGE - Centro de Investigação em Ciências Geo-Espaciais, Observatório Astronómico Prof. Manuel de Barros
}

\begin{abstract}
Resumo
Este artigo debruça-se sobre as potencialidades do sketching nos estudos de mobilidade. Começando por cruzar as preocupações e especificidades das metodologias móveis com as questões levantadas pelo uso das metodologias baseadas na arte em ciências sociais e em particular na sociologia, confronta-se este enquadramento teórico metodológico com a experiência de um workshop de metodologias móveis organizado no contexto de um seminário sobre mobilidades. Os resultados desta experiência fizeram emergir três temas que se afiguram centrais para a problematização do recurso ao desenho enquanto ferramenta ao serviço das metodologias móveis: o aparente determinismo imposto pelas competências e skills preexistentes; a importância do tempo na observação da passagem do tempo; e, por fim, as questões éticas associadas ao acto de desenhar in loco. Conclui-se com uma reflexão sobre os principais desafios que se colocam ao uso desta ferramenta na investigação social aplicada aos estudos de mobilidade.
\end{abstract}

Palavras-chave: métodos criativos, mobilidades, desenho, arte

\begin{abstract}
This article focuses on the potential of sketching for mobility studies. Crossing the concerns and specificities of mobile methodologies with the issues raised using arts-based methodologies in social sciences, particularly in sociology, we proceed to confront this framework with the experience of a mobile methodology workshop held in the context of a seminar on mobility. The results of this experiment led to the emergence of three central themes when discussing the role of drawing as a tool at the service of mobile methodologies: the apparent determinism imposed by pre-existing skills and abilities in the researcher; the importance of time when observing the passage of time; and, finally, the ethical issues associated with drawing on the spot. The paper ends with a reflection on the main challenges of the use of this tool in mobility studies' research.
\end{abstract}

Keywords: creative methods, mobilities, drawing, art 
The question is often asked, "Can every one learn to draw?" and although it may seem an ignorant question, it had better be answered. All persons who can learn to write can learn to draw. If it were required, "Can anyone become an artist?" the question might be answered by another, "Can anyone become a poet?"

William Walker (1880), Handbook of Drawing, pp. 3-4.

\section{Introdução}

Buscher e Urry (2009, p. 99) argumentam que o paradigma das mobilidades criou a necessidade de novos métodos e motivações para examinar importantes fenómenos, a par de novas sensibilidades empíricas, o que se consubstanciou na proposta de reflexão em torno do conceito de "metodologias móveis", forjado precisamente nesse texto. Este conceito veio agrupar perspectivas e técnicas que não eram necessariamente novas à data, mas que tinham em comum uma preocupação com a incorporação do movimento e da mobilidade na abordagem à realidade social, representando por isso um marco na reflexão metodológica em torno do estudo das mobilidades.

Em Novembro de 2018, no contexto mais amplo de um seminário internacional e interdisciplinar sobre mobilidade, decidimos ensaiar empiricamente um workshop sobre metodologias móveis ${ }^{1}$. Organizado em três momentos principais (orientação e partida, percurso, chegada e partilha), o workshop que foi original e propositadamente desenhado para esse seminário previa uma actividade de observação directa por parte dos participantes, a quem era solicitado que fizessem um breve percurso circular em volta do local de realização do seminário ou, em alternativa, que se fixassem num ponto de observação privilegiado nas imediações desse mesmo edifício. No total, dados os constrangimentos a que o programa científico do workshop obrigava, mas sobretudo devido à natureza eminentemente pedagógica do exercício proposto, foi consensualizado que a observação deveria cingir-se a um período de tempo reduzido, de aproximadamente quinze minutos. Munidos de um mapa com a representação gráfica da envolvente geográfica do edifício de onde partiram, aos participantes foi também entregue um marcador de feltro com o objectivo de traçarem o percurso efectuado ou o local por eles escolhido para a observação. Paralelamente, foram convidados a observar e registar mediante fotografia, gravação áudio, vídeo ou sob a forma de sketch (esboço) quaisquer elementos considerados relevantes em resultado de uma interpelação a partir das ideias de ritmo e dinâmica (interacções, movimentos e deslocamentos), pausa e estaticidade (encontros, sedentarismos, fixações), estética (sons, odores, cores, materiais e volumetrias) ou quaisquer associações livres com música, poesia e performance diversa. Os registos da observação foram feitos com recurso a funcionalidades tecnológicas diversas, nomeadamente as aplicações móveis disponíveis nos smartphones ou tablets pessoais. Desconhecendo as competências de desenho por parte dos participantes no workshop, o registo da observação através de sketch foi intencionalmente suscitado pela participação, a convite, de uma pessoa que se disponibilizou a fazer o diário gráfico do seminário². O workshop, divulgado no programa científico do seminário como o momento final do evento, contou com uma dúzia de participantes, os quais se envolveram voluntária e entusiasticamente na experiência, gerando interessantes partilhas no grupo. No final, já com todos os participantes em sala, os materiais recolhidos foram reunidos, projectados, visionados e comentados em registo de discussão aberta.

Este artigo toma como ponto de partida o contexto mais amplo de realização do workshop "Metodologias Móveis", para daí reflectir teórica e empiricamente sobre o potencial do sketching para os estudos de mobilidade. A discussão gerada durante a apresentação dos materiais recolhidos no workshop fez emergir três temas que se afiguram centrais para a problematização do recurso ao desenho observacional enquanto ferramenta ao serviço das metodologias móveis: o aparente determinismo imposto pelas competências e skills preexistentes por parte dos investigadores, nomeadamente a distinção entre os que "sabem" ou "têm jeito para" desenhar e os que "não sabem" ou "não têm jeito"; a importância do tempo na observação da passagem do tempo, particularmente a distinção entre uma observação rápida e/ou episódica e uma outra, de tipo intensivo e prolongada no tempo; e, por fim, as questões éticas associadas ao acto de desenhar in loco, nomeadamente as que envolvem o acesso à primeira vista "fácil" e "a-problemático" ao espaço público e seus intervenientes. Tendo em vista um desenvolvimento coerente e sustentado destas problemáticas, procuraremos, primeiro, reflectir sobre as diversas metodologias empregadas para captar empiricamente a mobilidade. Segue-se uma reflexão sobre o lugar do sktech no conjunto de estratégias criativas de investigação social, particularmente no que respeita à observação da mobilidade através e com recurso ao desenho. Por fim, utilizar-se-ão alguns dos registos efectuados em Novembro de 2018 para interpelar sociologicamente aqueles que são, em nosso entender, os principais desafios que se colocam ao uso desta ferramenta na investigação social aplicada aos estudos de mobilidade.

\section{Metodologias móveis: Conhecer o movimento, em movimento}

Durante muito tempo, a academia negligenciou o movimento e a sua relevância social, não apenas enquanto contexto e núcleo de fenómenos 
sociais - a deslocação é em si um fenómeno social e durante a deslocação acontecem fenómenos sociais -, mas também enquanto metodologia (Busher \& Urry, 2009). Estes autores defendem que se estude o movimento em si, mas também que se investigue em movimento, considerando que só experimentando o movimento os/as investigadores/ /as podem compreender "as mobilidades em suas várias manifestações" [itálico original] (Büscher \& Veloso, 2018, p. 134).

Usar e adequar métodos móveis à análise de fenómenos sociais numa abordagem sociológica nem sempre é fácil. Se a Antropologia, pelas suas próprias características enquanto disciplina científica, desde sempre tendeu a ter o movimento incorporado nos seus estudos, a começar pelos estudos fundadores que implicaram o viajar para ir ao encontro do objecto de estudo, a Sociologia, pelo seu forte enfoque nas estruturas sociais, bem como pelo relativamente recente reconhecimento da validade das abordagens qualitativas, tende a uma maior estaticidade (Sheller, 2015). Ainda assim, importa recordar que há na história da Sociologia abordagens que são mais eclécticas e que focam as questões da mobilidade, como a Escola de Chicago e os estudos de sociologia urbana, que foram precursores a trabalhar questões como a mobilidade residencial ou os movimentos pendulares. Autores como Park, Burgess e Simmel enfatizaram a importância da mobilidade enquanto contexto e fenómeno social (Sheller, 2014), e, se durante muito tempo estes estudos ficaram esquecidos, os apologistas de uma sociologia das mobilidades têm, nos últimos anos, recuperado estas análises como fonte de inspiração (Sheller, 2014).

Apesar da maior diversidade dos últimos anos, podemos dizer que a tendência mainstream da Sociologia tem sido no sentido de uma abordagem maioritariamente quantitativa e que a técnica de recolha de dados utilizada de forma mais recorrente se baseia na inquirição, numa abordagem de tipo word-based (Prosser \& Loxley, 2008), ou seja, que explora o discurso como fonte primária de conhecimento da realidade social. A ênfase é colocada principalmente na interacção social entre investigador-sujeitos observados, e pela importância do elemento discursivo são promovidos os locais reservados e calmos para a inquirição, não apenas porque favorecem uma maior concentração, mas também porque facilitam as condições de gravação áudio ou vídeo.

Contudo, o estudo sociológico do movimento e a afirmação do paradigma da mobilidade na Sociologia tem feito sentir a necessidade de abordagens metodológicas específicas, uma vez que a questão base - "como estudar pessoas em mobilidade?" levanta desafios particulares de operacionalização. A observação directa é muito eficaz para contextos de passagem; porém, não fornece a informação necessária quando se pretende compreender a perspectiva dos sujeitos sobre a mobilidade. Por outro lado, quando a escolha recai sobre a abordagem a estes sujeitos através de inquérito por questionário ou entrevista, tendemos a perder a objectividade da observação directa, bem como toda a ambiência passível de ser observada nos locais de passagem. A adaptação de técnicas que classicamente não são móveis a contextos de mobilidade, como a entrevista em mobilidade (Sales Oliveira, 2011) ou uma lógica de observação móvel que é impregnada pela perspectiva do investigador como "a sombra" (Jiron, 2011), são resultado destas preocupações.

O uso das metodologias visuais tem vindo a apresentar-se como promissor enquanto forma de captar e trabalhar o movimento. À semelhança do discurso, que a Sociologia analisa para tentar compreender as cognições, ideias e construções subjacentes, o movimento, expressivo de formas de fazer e viver, também exige análise, reflexão e desconstrução da investigação. Não basta deslocar-se com o objecto de estudo, é preciso questioná-lo depois, idealmente várias vezes, sem receio da particularidade do olhar de quem analisa. As metodologias visuais permitem isso: uma fotografia pode ser vista e revista. De acordo com Prosser e Loxley (2008), passámos de uma primeira fase, em que se considerava que os métodos visuais captavam acrítica e objectivamente a realidade, para uma postura mais reflexiva, em que se compreende a subjectividade inerente ao olhar do investigador, não apenas quando interpreta a imagem, mas desde logo no momento em que a capta. Actualmente considera-se já ter evoluído de um estádio de uso da fotografia como mera ilustração de ideias ou até decoração para uma modalidade mais interpelativa da realidade social através das metodologias visuais (Prosser \& Loxley, 2008).

\section{Observar a realidade social, desenhando}

Existe uma longa tradição de observação e registo da realidade social através do desenho. Muito frequentemente, marinheiros, viajantes, comerciantes e missionários usaram o desenho como forma de registar o confronto com "o outro" (Soukup, 2014). Em contexto académico, disciplinas várias das ciências naturais, nomeadamente a biologia e a botânica, mas também a geografia física, a arqueologia e a arquitectura incorporam uma longa história de recurso ao desenho observacional como ferramenta de investigação em campo (Heath, Chapman \& The Morgan Centre Sketchers, 2018). Entre as ciências sociais, é na Antropologia que historicamente encontramos uma tradição mais forte e uma maior permanência do recurso ao desenho enquanto técnica observacional (Kuschnir, 2016a; 
Pink, Kürti \& Afonso, 2004). Uma forma particular de desenho, o "desenho etnográfico", foi utilizado desde os finais do século XIX para significar o desenho realizado por etnógrafos em trabalho de campo e detalhar determinadas características consideradas distintivas ou especiais de pessoas ou artefactos, incluindo desde desenhos anatómicos a representações da cultura material, diagramas e gráficos de parentesco (Azevedo, 2016a; Soukup, 2014). Porém, os desenvolvimentos ocorridos durante a segunda metade do século $\mathrm{XX}$ remeteram o desenho para segundo plano na apresentação dos particularismos antropológicos (Heath et al., 2018; Soukup, 2014), substituídos paulatinamente pela fotografia e pelo vídeo, os quais registaram um desenvolvimento notável no quadro dos chamados estudos visuais.

Os últimos anos têm registado um aumento da visibilidade dada ao desenho observacional em contexto de investigação científica. Esta visibilidade é particularmente notória nos estudos antropológicos e etnográficos, de tal forma que alguns autores falam mesmo de uma viragem gráfica (Ballard, 2013) para significar a revitalização do campo por essa via, principalmente com os trabalhos de Taussig (2011) e Ingold (2011). De Portugal, aliás, partiu um contributo especialmente relevante para essa viragem, com os trabalhos de Manuel João Ramos (2004, 2009, 2010) a serem insignemente reconhecidos e valorizados entre os seus pares (Kuschnir 2016a, 2016b; Pink et al., 2004).

No que respeita ao campo disciplinar da Sociologia, o desenho observacional tem sido parcamente utilizado (Heath et al., 2018). Apesar disso, não é incomum aos sociólogos fazerem esboços aproximados à realidade, muito embora tais esboços apareçam principalmente como anotações informais do trabalho de campo e com menor protagonismo aquando da apresentação de resultados de investigação (Heath et al., 2018). Ainda assim, nos últimos anos tem-se observado um incremento no uso desta técnica, em grande medida tributário de uma frescura suscitada pelo desenvolvimento das metodologias criativas de investigação social (Kara, 2015), bem como de uma maior ênfase na sociologia enquanto arte de contar histórias (Becker, 2007; Berger \& Quinney, 2004).

As metodologias criativas de investigação social cobrem um leque diversificado de técnicas e abordagens em desenvolvimento permanente e dinâmico ao longo dos últimos vinte anos (Denzin \& Lincoln, 2011; Kara, 2015; Mason, 2002; Mason \& Dale, 2011). Resultam principalmente do reforço da pesquisa em equipas multi e interdisciplinares e, consequentemente, da necessidade de ultrapassar as fronteiras, métodos e técnicas tradicionais, tendo em vista responder à complexidade crescente das questões de investigação em ciências sociais (Kara, 2015). Estas metodologias têm beneficiado de um contexto mais amplo de valorização dos valores associados à inovação e da aplicação dos princípios do design thinking a inúmeras esferas do social que não apenas a produção industrial ou as práticas artísticas (Mäkelä, Nimkulrat \& Heikkinen, 2014).

Por metodologias criativas entende-se um conjunto vasto de metodologias não necessariamente novas na história da investigação social. Há que distinguir entre criatividade e inovação, e, de facto, a maior parte das metodologias criativas são mais criativas do que inovadoras (Kara, 2015). Apesar das dificuldades associadas à definição de criatividade, acrescidas pela variabilidade temporal, espacial e cultural do conceito, existe relativo consenso quanto ao facto de a criatividade ser mais um processo do que um resultado, já que implica a criação de algo a partir de elementos que já existem, dispondo-os ou articulando-os em combinações diferentes tendo em vista a resolução de questões ou problemas específicos (Kara, 2015).

Helen Kara propõe uma reconceptualização dos métodos de pesquisa criativa em quatro áreas (Kara, 2015, p. 3): a pesquisa baseada na arte (arts-based research), a pesquisa que usa a tecnologia, a pesquisa apoiada em estudos mistos e os contextos transformativos de investigação, os quais incluem metodologias que atendem a factores contextuais específicos por forma a tornar a investigação mais "democrática" ou "justa", como sejam as metodologias apelidadas de "participativas", "feministas" ou "descolonizadoras", sem que no entanto estas quatro áreas possam ser vistas como mutuamente exclusivas. Por exemplo, muitas vezes as pesquisas envolvem a combinação de várias técnicas, eventualmente com recurso a tecnologias diversas de interpelação ou registo do social, e em contextos que acentuam relações desiguais entre quem observa e quem é observado, seja por força de variáveis como o poder, género, etnia, ou por uma certa transversalidade da condição de vulnerabilidade dos sujeitos observados.

Resultado de uma aproximação entre os cientistas sociais e os artistas e performers, o recurso à arte na investigação científica significa "o uso sistemático de processos artísticos como forma primária de entendimento e análise de experiências pelos investigadores e pelas pessoas envolvidas na investigação" (McNiff, 2008, p. 29). As artes visuais, nomeadamente o desenho, a pintura, as colagens ou a fotografia, assim como as artes teatrais e performativas, incluindo a música, drama, cenografia e diversas formas de performance artística, escrita criativa (ficcional e não ficcional) e poesia têm sido utilizadas em contextos diversos de investigação com o intuito de aprofundar a compreensão sobre a realidade social. Investigar através da arte privilegia a criatividade, o jogo, a intuição, o acaso, a imaginação e o tirar partido de recursos inesperados (Kara, 2015). Estes recursos parecem fundamentais 
na leitura do real-social, muito particularmente numa perspectiva qualitativa que visa um conhecimento em profundidade e intensidade, holístico e assente numa compreensão dos fenómenos "a partir de dentro" (Denzin \& Lincoln, 2011). Ainda assim, obrigam a uma explicitação clara e detalhada das razões que fundamentam o seu uso, bem como das formas de operacionalização que envolvem (Prosser \& Loxley, 2008, p. 35). Para Helen Kara, os métodos de investigação criativa baseados na arte são particularmente aptos para explorar tópicos sensíveis, incluindo os que lidam directamente com a emoção, trabalhar com sujeitos cuja língua nativa é diferente da língua em que a pesquisa é conduzida, que usam línguas diferentes entre si, que têm deficiências cognitivas, na pesquisa com crianças e na busca pela expressão de formas culturais idiossincráticas de conhecimento (Kara, 2015, p. 24).

O desenho observacional enquadra-se de forma mais clara na pesquisa baseada na arte. Por desenho entende-se uma criação composta por linhas e sombras (Gunn, 2009). Desenhar envolve desde logo diversidade, visível no estilo ou tipo de narrativa gráfica, que pode ser mais sequencial ou episódica, no conhecimento técnico do desenho ou destreza de quem desenha, nos materiais utilizados, suportes, utilização ou ausência de palavras (Azevedo, 2016a). Comparativamente ao desenho profissional, o sketching é comummente caracterizado por uma maior liberdade e criatividade (Gunn, 2009; Kuschnir, 2012). Desenhar, como dançar, é um processo exploratório e construtivo (Mäkelä et al., 2014), que implica um engajamento activo e subjectivo entre o observador e a coisa ou ideia observada num determinado espaço-tempo.

A reflexão em torno da coexistência ao longo de um ano entre a artista Lynne Chapman e os investigadores do Morgan Centre for Research into Everyday Lives em Manchester levou Sue Heath e os seus colaboradores a destacar três temas principais (Heath et al., 2018, p. 717). Desenhabilidade ("sketchiness") diz respeito à natureza distintiva dos dados gerados através do sketch quando comparado a outros métodos visuais; foco ("concentrated seeing") remete para o processo através do qual esses dados são gerados, processo esse que instiga novas formas de aprender a ver; por fim, o terceiro tema enfatiza a interacção e imersão no contexto social de produção do desenho, contexto esse que usualmente envolve outras pessoas, as quais desempenham um importante papel na construção dos dados.

Tendo por base a experiência de organização e condução de um workshop participativo, as co-autoras deste texto - duas sociólogas e a sketcher convidada - analisaram e reflectiram sobre os seus outputs, nomeadamente sobre os desenhos enquanto resultado, mas também sobre o próprio processo de observação e registo da observação, em concreto sobre a especificidade do "desenhar" comparativamente a outras formas de observar. A reflexão que se segue explora três temas que animaram a discussão entre os participantes e que se nos afiguram centrais para a problematização do recurso ao desenho observacional enquanto ferramenta ao serviço dos estudos de mobilidade: o aparente determinismo imposto pelas competências e skills preexistentes por parte dos investigadores; a importância do tempo na observação da passagem do tempo; e, por fim, um conjunto de questões éticas associadas ao desenho observacional in loco.

\section{Desenhando mobilidades}

Desenhar, fotografar, escrever?

Aina Azevedo diz que, se não soubermos que podemos desenhar, talvez não o façamos (Azevedo, 2016b). Esta afirmação é peremptória sobre o modo como a tomada de consciência individual ou disciplinar para a (in)capacidade de desenhar condiciona a efectiva possibilidade de o fazer. A literatura aponta, aliás, nesse mesmo sentido, reconhecendo que uma relação bem-sucedida entre o recurso ao desenho implica quase sempre que os investigadores reúnam a priori os skills para o efeito (Kara, 2015). O mesmo não acontece com outras formas importantes de registo observacional, simultaneamente presentes na vida de todos os dias e em investigação científica, como o recurso à câmara fotográfica ou à escrita. Por um lado, no contexto actual, marcado pela ubiquidade de smartphones equipados com uma tecnologia de ponta ao nível da imagem, focagem e facilidade de utilização, todos, inclusive os investigadores, parecem "natural" e "igualmente" fotógrafos (Costa, 2019; Jurgenson, 2019). Por outro, a escrita parece também uma competência dada por adquirida entre investigadores, não sendo a sua mestria colocada como impedimento à tomada de notas como a distinção entre os que "sabem" ou "têm jeito para" desenhar e os que "não sabem" ou "não têm jeito" habitualmente o é (Geismar, 2014; Kara, 2015).

Tomando estas ideias como ponto de partida, o desenho "A carrinha do pão e o camião das mudanças" (Figura 1) oferece-se como uma alternativa à narrativa escrita, ao informar visualmente o leitor acerca da identificação de obstáculos à mobilidade pedonal numa determinada zona da cidade de Évora ${ }^{3}$. Porém, como qualquer produto artístico, a apreciação do conteúdo parece dependente de uma apreciação estética imediata sobre a qualidade do mesmo. "O que vemos neste desenho?" parece indissociável da questão "Qual a qualidade deste desenho?". De que forma é que o conjunto de traços, sombras e cores oferece uma representação "excelente", "boa", "sufi- 
ciente" ou "real" do "real-social"? E até que ponto é isso importante?

O visual "nunca é inocente" (Rose, 2001, p. 32), no sentido em que é sempre construído através de práticas, tecnologias e conhecimentos específicos. No caso particular do estudo das mobilidades, o recurso ao sketch parece ganhar força no argumento de que não é necessário ser um bom desenhador de quem o observa. No desenho "Caminhantes à chuva, capacete de ciclista e estacionamento concorrido" (Figura 2) foram registados elementos aparentemente avulsos em torno da observação do movimento de pessoas no espaço físico: homens, mulheres e artefactos como o chapéu-de-chuva, boné e gabardina; o espaço aberto e público da rua e o espaço fechado e privado aqui representado

Figura $1 \triangleright$ A carrinha do pão e o camião das mudanças

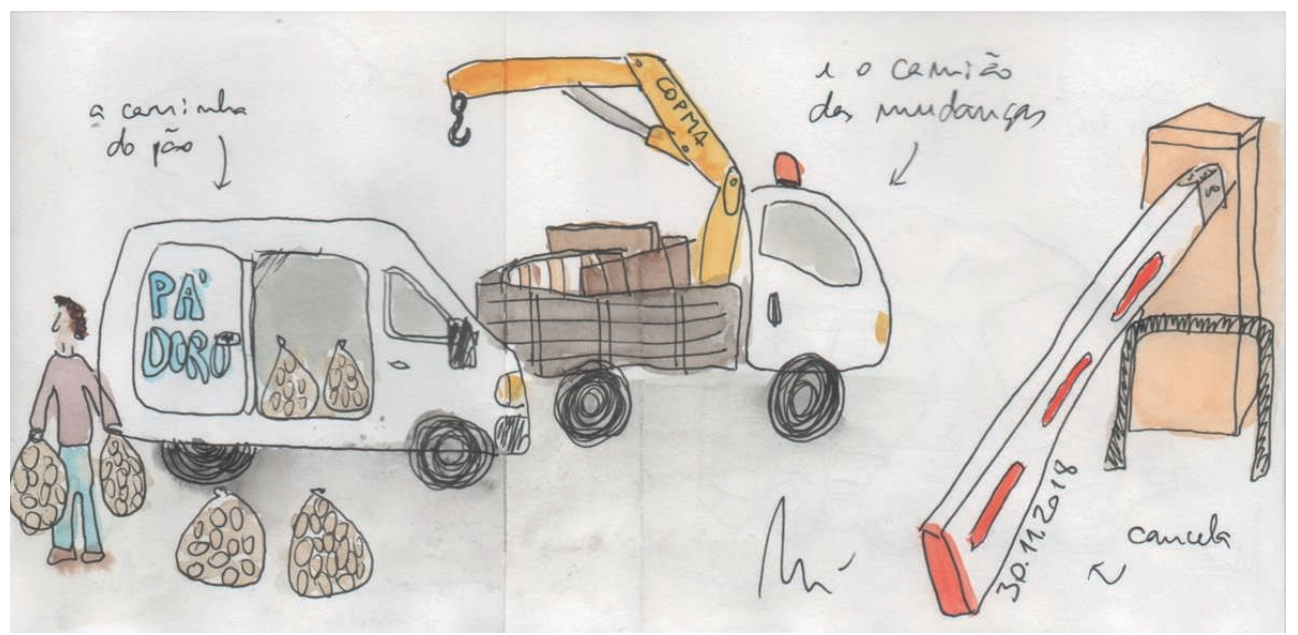

Fonte: A. Márcia Barbosa, 2018.

para obter uma representação gráfica da realidade (Kuschnir, 2012), e de que os métodos baseados em arte, nomeadamente o desenho, podem ser utilizados por quaisquer investigadores, desde que apropriados à pesquisa e seu contexto (Kara, 2015). Mais do que a técnica, qualidade gráfica ou realismo, o desenho observacional vale por si mesmo enquanto forma de conhecimento e de interpelação do real (Taussig, 2009). Deste ponto de vista, todos os investigadores estão aptos a representar de alguma forma aquilo que observam. Acresce que as competências ao nível do desenho não são inatas e podem ser adquiridas ou aperfeiçoadas em contextos vários, como testemunham as experiências de associação de alguns investigadores ao movimento Urban Sketchers (Campanario, 2012; Heath et al., 2018) ou a organização em contexto académico de cursos propositadamente pensados para o efeito, como o "Laboratório de Antropologia e Desenho", organizado por Karina Kuschnir na Universidade Federal do Rio de Janeiro (Kuschnir, 2014).

Observar o tempo que passa, registar o tempo que fica

Usar o sketch para registar a mobilidade faz emergir considerações em torno das formas de observação e apropriação do tempo por parte pela secretária e cadeiras numa sala de aula; mas também as possibilidades e interditos associados a tal movimento, expressos no sinal de trânsito de estrada sem saída, no calçado que ora promove, ora obstaculiza a mobilidade, bem como as exigências colocadas sobre uma mobilidade "segura" e "regulada", como iconicamente representa o capacete, o congestionamento de tráfego no parque de estacionamento e o eventual choque entre viaturas. Como pode a estaticidade, rigidez e parcialidade de um desenho ajudar a compreender o tempo na sua complexidade e multidimensionalidade?

As múltiplas reflexões para que esta figura remete patenteiam de modo evidente como o desenho visto como produto é indissociável do acto de desenhar enquanto processo. Para Berger (2005), no acto de desenhar vale principalmente o processo, não o resultado, isto é, aquilo que o desenhador passa a ver e a conhecer com base na experiência de desenhar e num diálogo que se estabelece entre o observador e aquilo que é observado. Conjugar o verbo desenhar implica e consome tempo. A boa fotografia ou escrita também, muito embora a tecnologia das máquinas fotográficas digitais e dos processadores de texto actuais cause uma ilusão de que assim não é (Soukup, 2014). Porém, enquanto desenhar é um processo que consome tempo, a fotografia "congela esse tempo" (Berger, 2005, p. 70). 
Figura $2 \triangleright$ Caminhantes à chuva, capacete de ciclista e estacionamento concorrido

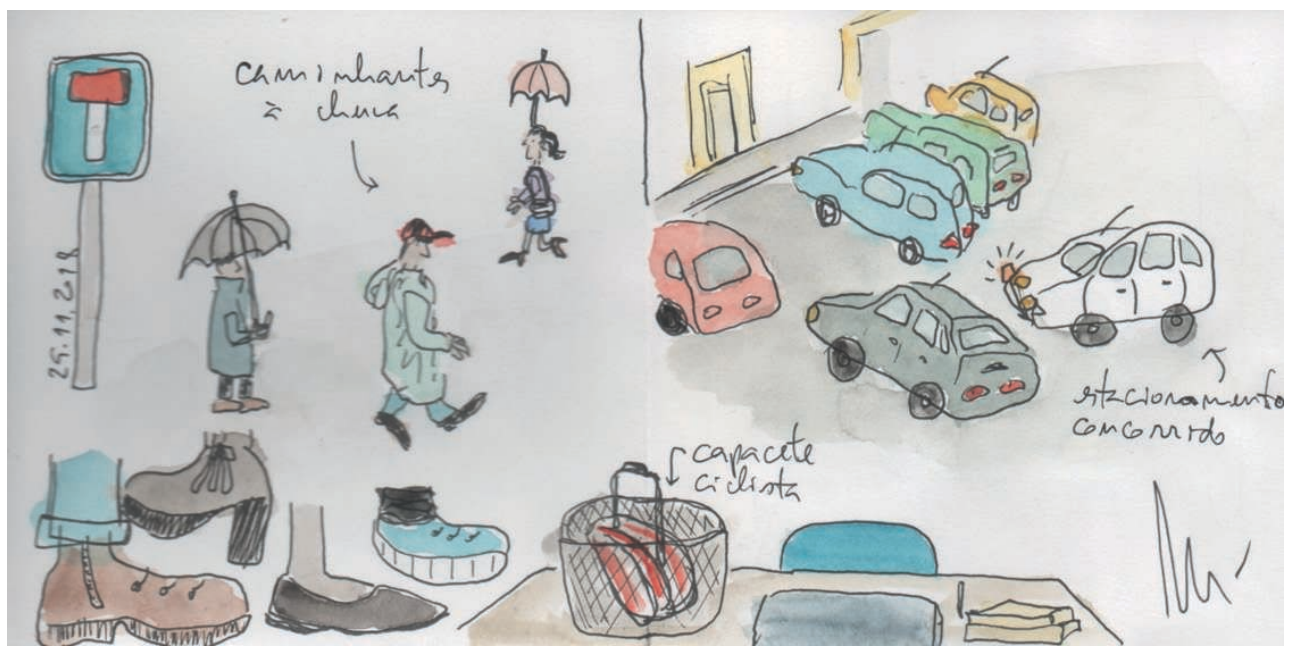

Fonte: A. Márcia Barbosa, 2018.

Taussig considera que o poder do desenho está em revelar exactamente "aquilo que escapa à fotografia" (Taussig, 2011, p. 31) com destaque, aqui, para o modo de agregar num só tempo múltiplos tempos, inclusive um certo esvaziamento do tempo relativamente ao espaço. Como afirma Karina Kuschnir, os desenhos são simultaneamente "formas de ver e formas de conhecer o mundo" (Kuschnir, 2016b, p. 105). De modo transversal, o tempo está no cerne do desenho enquanto técnica que pretende captá-lo ou estudá-lo. Há uma contiguidade quase intuitiva entre a tradição qualitativa de inspiração etnográfica e o desenho pela via de um trabalho intensivo e imersivo no campo (Kuschnir, 2016b). Por esta via também, o desenho aproxima-se do movimento contemporâneo que apela à importância do tempo longo no processo e reflexão científica (The Slow Science Academy, 2010).

Desenhar com e sem licença e a ética no sketching

Desenhar in loco suscita interrogações várias sobre o acesso à primeira vista "fácil" e "a-problemático" ao espaço público e seus intervenientes comparativamente a espaços privados ou regulados por instâncias exteriores ao investigador. O desenho "Descanso, carrinho de bebé e tuc-tuc" (Figura 3) ilustra questões múltiplas em torno da sobreposição de tempos no espaço: o tempo de lazer para os turistas e o tempo do trabalho para o motorista do tuc-tuc; o tempo repetido das rotinas familiares do dia-a-dia do homem que transporta o bebé e a excepção no quotidiano que o turismo representa; o tempo lento e ditado pelos ritmos humanos dos percursos pedonais e o tempo apressado e automa- tizado dos meios de transporte e tecnologias digitais presentes na cidade.

Desenhar é uma forma aparentemente simples, fácil e rápida de aceder ao campo no espaço público. Dispensa autorizações e burocracias, não está sujeito a horários de abertura e fecho, tão-pouco obriga à disponibilização por parte de outros de um espaço onde o investigador se possa instalar. Adicionalmente, permite ultrapassar aquele que é um obstáculo por vezes substantivo no acesso ao campo: o consentimento informado por parte dos sujeitos observados e a consequente garantia de anonimato que a voz ou rosto frequentemente denuncia (ESRC, 2011).

Em Portugal, a fotografia de rua - lugares públicos - é admissível legalmente (Pereira, 2016). Ainda assim, fotografar pessoas em locais públicos é um acto explícito, percepcionado por quem passa. Pode gerar perplexidade, eventualmente desconforto, porque a pessoa fotografada, apesar de estar em espaço público, não espera que a sua imagem seja captada. Apesar de ser possível concretizar o anonimato a posteriori, nomeadamente através de técnicas de desfocagem da imagem, obter o consentimento informado é difícil e por vezes quase impossível, como por exemplo aquando de uma curta viagem de autocarro. Permanece então um debate ético/moral intrínseco ao investigador que, mesmo sabendo que pode fotografar em lugares públicos, poderá ou não sentir esta questão como problemática, dependendo do seu quadro moral de referência (Wiles et al., 2008). Equacionando o aspecto moral, é legítimo considerar que ser fotografado significa uma perda de intimidade e privacidade porque se captam expressões, posições do corpo, contextos, encontros (Sales Oliveira, 2015). Por compreender 
Figura $3 \triangleright$ Descanso, carrinho de bebé e tuc-tuc

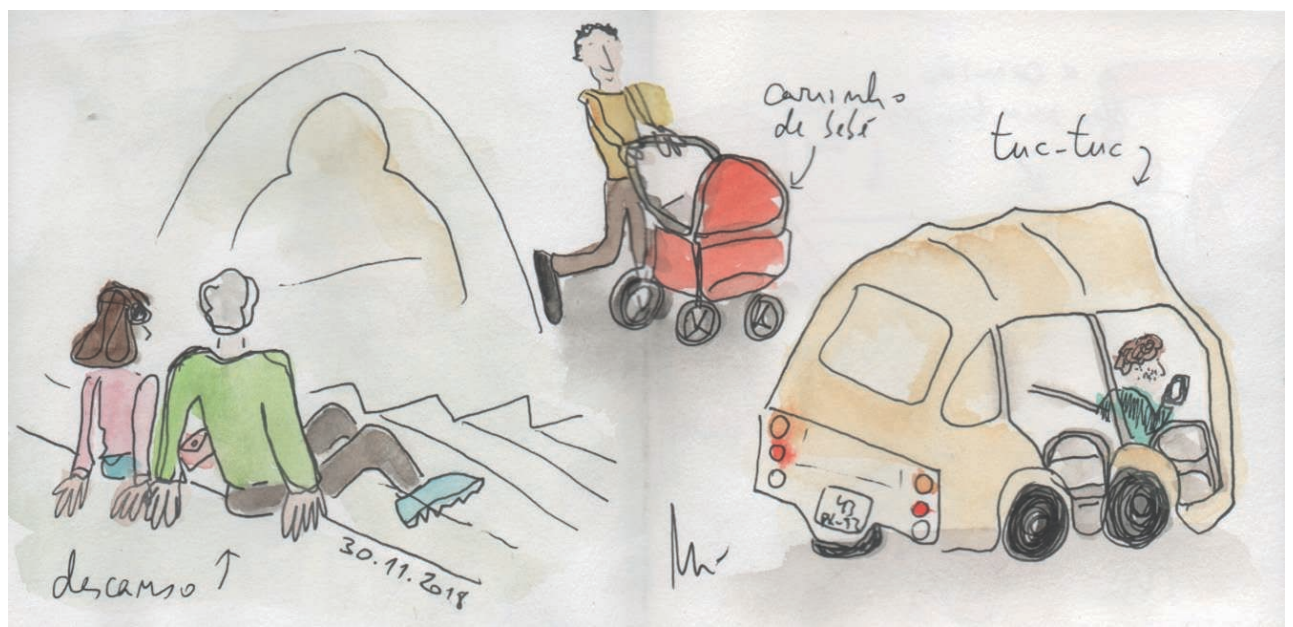

Fonte: A. Márcia Barbosa, 2018.

isto e também porque a percepção da câmara altera o comportamento das pessoas estudadas, o investigador pode tender a passar despercebido, tirar fotos discretamente, penalizando a qualidade e oportunidade das mesmas e arriscando enfrentar verdadeiros embaraços quando uma das pessoas fotografadas se apercebe do que está a acontecer. Por todas estas razões, a investigação visual, e o desenho em particular, entronca necessariamente num posicionamento ético que apela ao estabelecimento de relações colaborativas na investigação, isto é, que se aproximam de uma abordagem do tipo ética do cuidado (Wiles et al., 2008).

\section{Conclusão}

I almost cannot think when I stay in place; my body needs to be in motion for my mind to be there.

Jean-Jacques Rousseau

Procurou-se neste artigo tratar a forma como a mobilidade desafia as abordagens metodológicas mais tradicionais da Sociologia, pedindo, pela sua própria essência, uma interpelação que contemple intrinsecamente o movimento. A perspectiva das metodologias criativas, mais especificamente a arts-based research, foi elencada de modo a reflectir em que medida o sketching pode representar uma mais-valia e trazer uma lufada de ar fresco ao trabalho de campo sociológico nesta área específica dos mobility studies.

A experiência de organização e condução de um workshop de metodologias móveis em 2018 funcionou como alicerce para um debate em que se destacaram três temas centrais: a maior ou menor relevância das competências de desenho, a importância do tempo ao desenhar a mobilidade e as questões éticas levantadas pelo sketching observacional com o objectivo de pesquisa científica. Consensualizou-se que se trata de uma técnica ao alcance de todos os que se interessem por aprendê-la ou praticá-la, passível de captar a multiplicidade de tempos, espaços e ambiências da experiência social da mobilidade e os seus protagonistas, e que eticamente apresenta vantagens perante a fotografia pela sua menor intrusividade. A preocupação com o seu uso é comum ao uso de metodologias visuais e criativas em geral e prende-se sobretudo com a subjectividade inerente.

Como nos diz Azevedo, "para alguns, o desenho é um verbo, um fazer, um processo, uma metodologia de pesquisa; para outros, o desenho é um resultado de pesquisa e uma forma, inclusive, de apresentá-la; para muitos, o desenho é ambas as coisas" (2016a, p. 22). Ao desenhar um entorno em mobilidade, o investigador, que normalmente tem de estar parado para executar o acto, está, no entanto, em movimento interior, em processo de conhecimento e simultaneamente em processo criativo, na medida em que um desenho é o resultado de uma visão do mundo. Desta forma, a aparente estaticidade do acto de desenhar consubstancia uma performance e a experiência de desenhar é então um diálogo que se estabelece entre o observador e aquilo que é observado, em que o primeiro absorve o que o rodeia, processa-o e expressa-o em linhas passíveis de interpretações diversas num movimento contínuo e criativo. O real-social é assim interpretado e em certa medida (re)produzido pelo observador/ /investigador que se torna parte do desenho. Assim, pleno de subjectividade, o desenho da realidade social, neste caso em movimento, constitui o olhar 
do investigador que consubstancia o seu objecto de estudo numa imagem que leva consigo e pode reinterpretar e questionar posteriormente. É neste sentido que propomos que o uso do sketching exalta a perspectiva da slow academy, incitando à calma e ao vagar de percorrer folhas com traços sem tempo marcado e depois revisitar esses esboços as vezes que forem necessárias ou desejadas. Justamente porque desenhar é um acto performativo em si, afigura-se-nos particularmente adequado o desafio de desenhar a mobilidade.

\section{Notas}

1 O workshop citado intitulou-se "Metodologias Móveis" e foi co-organizado a 30 de Novembro de 2018 por Dennis Zuev, Catarina Sales Oliveira, Daniel Malet Calvo, Rosalina Costa e A. Márcia Barbosa.

2 Este convite foi inspirado pela tomada de conhecimento da residência artística de Lynne Chapman no Morgan Centre for Research into Everyday Lives, em Manchester, durante o ano académico 2015/16. O resultado de um ano de convívio entre uma sketcher e um grupo de investigadores focados em metodologias qualitativas, sensoriais e criativas pode ser encontrado no artigo "Observational sketching as method" (Heath et al., 2018) e no blogue da artista em https:// lynnechapman.blogspot.co.uk. A. Márcia Barbosa, co-autora deste texto, foi a "sketcher em trânsito" durante os três dias de seminário realizado em Novembro de 2018.

3 Todas as imagens reproduzidas neste artigo foram criadas em cores usando aguarelas e caneta.

\section{Referências bibliográficas}

Azevedo, A. (2016a). Desenho e antropologia: Recuperação histórica e momento atual. Cadernos de Arte e Antropologia, 5(2), 15-32.

Azevedo, A. (2016b). Um convite à antropologia desenhada. METAgraphias: Metalinguagem e outras figuras, 1(1), 194-208.

Ballard, C. (2013). The return of the past: On drawing and dialogical history. The Asia Pacific Journal of Anthropology, 14(2), 136-148. doi: 10.1080/14442213.2013.769119

Becker, H. S. (2007). Telling about society. Chicago: University of Chicago Press.

Berger, J. (2005). Berger on drawing. Aghabullogue: Occasional Press.

Berger, R. J., \& Quinney, R. (Eds.). (2004). Storytelling sociology: Narrative as social inquiry. Boulder: Lynne Rienner Publishers.

Büscher, M., \& Urry, J. (2009). Mobile methods and the empirical. European Journal of Social Theory, 1, 99-116. doi: $10.1177 / 1368431008099642$

Buscher, M., \& Veloso, L. (2018). Métodos móveis. Tempo Social, 30, 133-151. doi: 10.11606/0103-2070. ts. 2018.142258
Campanario, G. (2012). The art of urban sketching: Drawing on location around the world. Beverly: Quarry Books.

Costa, R. (2019). iPhone, iResearch. Exploring the use of smart phones in the teaching and learning of visual qualitative methodologies. Journal of Visual Literacy, 38(1-2), 153-162. doi: 10.1080/1051144X.2019.1567073

Denzin, N., \& Lincoln, Y. (2011). The Sage handbook of qualitative research (4. ${ }^{\mathrm{a}}$ ed.). Thousand Oaks, CA: Sage.

ESRC. (2011). The research ethics guidebook: A resource for social scientists. Disponível em http://www. ethicsguidebook.ac.uk/

Geismar, H. (2014). Drawing it out. Visual Anthropological Review, 30(2), 96-113. doi: 10.1111/var.12041

Gunn, W. (Ed.). (2009). Fieldnotes and sketchbooks - Challenging the boundaries between descriptions and processes of describing. Frankfurt: Peter Lang.

Heath, S., Chapman, L., \& The Morgan Centre Sketchers (2018). Observational sketching as method. International Journal of Social Research Methodology, 21(6), 713-728. doi: 10.1080/13645579.2018.1484990

Ingold, T. (2011). Being alive - Essays on movement, knowledge and description. Londres e Nova Iorque: Routledge.

Jiron, P. (2011). On becoming "la sombra/the shadow". In M. Büscher, J. Urry \& K. Witchger (Eds.), Mobile methods (pp. 36-53). Londres: Routledge.

Jurgenson, N. (2019). The social photo: On photography and social media hardcover. Londres: Bloomsbury.

Kara, H. (2015). Creative research methods in the social sciences. A pratical guide. Bristol: Polity Press.

Kuschnir, K. (2012). Desenhando cidades. Revista Sociologia \& Antropologia, 2(4), 295-314.

Kuschnir, K. (2014). Ensinando antropólogos a desenhar: Uma experiência didática e de pesquisa. Cadernos de Arte e Antropologia, 3(2), 23-46.

Kuschnir, K. (2016a). A antropologia pelo desenho: Experiências visuais e etnográficas. Cadernos de Arte e Antropologia, 5(2), 5-13.

Kuschnir, K. (2016b). Ethnographic drawing: Eleven benefits of using a sketchbook for fieldwork. Visual Anthropology, 5(1), 103-134. doi: 10.12835/ ve2016.1-0060

Mäkelä, M., Nimkulrat, N., \& Heikkinen, T. (2014). Editorial/drawing as a research tool: Making and understanding in art and design practice. Studies in Material Thinking, 10, 3-12. http://www. materialthinking.org/papers/147

Mason, J. (2002). Qualitative researching (2. ${ }^{a}$ ed.). Londres: Sage.

Mason, J., \& Dale, A. (2011). Understanding social research: Thinking creatively about method. Londres: Sage. 
McNiff, S. (2008). Art-based research. In J. G. Knowles, \& L. C. Ardra (Eds.), Handbook of the arts in qualitative research: Perspectives, methodologies, examples, and issues. Londres: Sage. doi: 10.4135/9781452226545.n3

Pereira, M. S. (2016). Direito a fotografar em Portugal. Lisboa: Instituto Português de Fotografia.

Pink, S., Kürti, L., \& Afonso, A. I. (Eds). (2004). Working images: Visual Research and representation in ethnography. Londres e Nova Iorque: Routledge.

Prosser, J., \& Loxley, A. (2008). Introducing visual methods. NCRM Discussion Paper. Southampton: ESCR. Disponível em http://eprints.ncrm. ac.uk/420/

Ramos, M. J. (2004). Drawing the lines: The limitations of intercultural ekphrasis. In S. Pink, L. Kürti, \& A. I. Afonso (Eds.), Working images: Visual research and representation in ethnography (pp. 147-161). Londres e Nova Iorque: Routledge.

Ramos, M. J. (2009). Traços de viagem: Experiências remotas, locais invulgares. Lisboa: Bertrand.

Ramos, M. J. (2010) Histórias etíopes. Lisboa: Tinta-da-China.

Rose, G. (2001). Visual methodologies. Londres: Sage.

Sales Oliveira, C. (2011). Mobilidade e classe(s) média(s) em contexto metropolitano (tese de doutoramento). Lisboa: ISCTE.

Sales Oliveira, C. (2015). No entretanto ou o (ab)uso do acesso online em mobilidade. Comunicação e Sociedade, 28, 229-250. doi: 10.17231/comsoc. $28(2015) .2279$

Sheller, M. (2014). Sociology after the mobilities turn. The Routledge handbook of mobilities. Londres: Routledge.

Sheller, M. (2015). Vital methodologies: Live methods, mobile art, and research-creation. In P. Vannini (Ed.), On-representational methodologies: Re-envisioning research (pp. 130-145). Londres: Routledge.

Soukup, M. (2014). Photography and drawing in anthropology. Slovak Ethnology/Slovensky Narodopis, 62(4), 534-546.

Taussig, M. (2009). What do drawings want?. Culture, Theory and Critique, 50(2-3), 263-274. doi: $10.1080 / 14735780903240299$

Taussig, M. (2011). I swear I saw this. Drawings in fieldwork notebooks, namely my own. Chicago e Londres: The University of Chicago Press.

The Slow Science Academy. (2010). The slow science manifesto. Berlim: The Slow Science Academy. Disponível em http://slow-science.org/

Walker, W. (1880). Handbook of drawing. Nova Iorque: Charles Scribner's Sons. Disponível em www. forgottenbooks.org

Wiles, R., Prosser, J., Bagnoli, A., Clark, A., Davies, K., Holland, S., \& Renold, E. (2008). Visual ethics: Ethical issues in visual research (NCRM Working Paper). Southampton: ESCR. Disponível em http:// eprints.ncrm.ac.uk/421/

\section{Rosalina Pisco Costa.}

Departamento de Sociologia, Universidade de Évora \& CICS.NOVA.UÉvora - Centro Interdisciplinar de Ciências Sociais. Largo dos Colegiais, 7002-554 Évora, Portugal. Email: rosalina@uevora.pt

Catarina Sales Oliveira. Faculdade de Ciências Sociais e Humanas, Universidade da Beira Interior \& CIES-IUL - Centro de Investigação e Estudos de Sociologia. Rua Marquês D'Ávila e Bolama, 6201-001 Covilhã, Portugal. Email: csbo@ubi.pt

A. Márcia Barbosa. CICGE - Centro de Investigação em Ciências Geo-Espaciais \& Observatório Astronómico Prof. Manuel de Barros. Alameda do Monte da Virgem, 4430-146 Vila Nova de Gaia, Portugal. Email: anamarciabarbosa@ gmail.com 